\title{
COMMERCIAL CULTIVATION BY FARMERS OF MEDICINAL PLANTS IN NORTHERN BANGLADESH
}

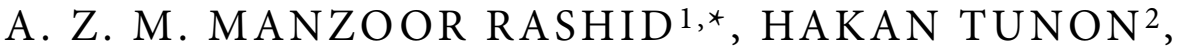 \\ NIAZ AHMED KHAN ${ }^{3}$, and SHARIF AHMED MUKUL ${ }^{4}$
}

\author{
${ }^{1}$ Department of Forestry and Environmental Science, Shahjalal University of Science and Technology, Sylhet-3114, Bangladesh \\ ${ }^{2}$ NAPTEK, Swedish University for Agricultural Sciences, Uppsala, Sweden \\ ${ }^{3}$ Department of Development Studies, University of Dhaka, Dhaka-1000, Bangladesh \\ ${ }^{4}$ School of Agriculture and Food Sciences, University of Queensland, Australia \\ *Corresponding author: pollen_forest@yahoo.com
}

\begin{abstract}
Medicinal plants (MPs) are an important component of non-timber forest products (NTFPs), which are traditionally used in healthcare and source of livelihood all over the world. In an over-populated country like Bangladesh, the pressure on natural forests is immense; thus the cultivation of MPs can significantly contribute towards improving the livelihood of poor people, reducing the pressure on natural forests and enhancing biological diversity. Notwithstanding the growing recognition of its importance and economic and ecological potential, there has been little research on MPs, especially the cultivation, management and marketing aspects, in Bangladesh. Based on extensive fieldwork in a northern district of Bangladesh, this study explores various aspects of the cultivation, management and marketing of MPs. How collective efforts have brought economic and social benefits to communities was also examined in this study. It assesses the major processes and elements of management, identifies key problems and challenges and indicates ways of maximizing the potential of this important sector. The issues covered in this research include: farmers' perceptions and experiences; existing research and policy-making processes related to the MP sector; constraining factors (such as lack of processing technology, inadequate transportation, logistics, financial and storage infrastructure, lack of institutional capacity); markets, finance and networking; land use; pattern of livelihood and value chain issue.
\end{abstract}

Keywords: medicinal plants, Bangladesh, cultivation, farmer, marketing, policy and conservation

\section{Introduction}

Traditionally forests and forest products have been important in maintaining the livelihoods of people and are still of paramount importance for local communities (Iftekhar 2006). According to the World Bank (2002), more than 1.6 billion people throughout the world rely to some extent on forests for their livelihoods and 350 million depend entirely on forests, both for their subsistence and income. Forestry employs about 12.9 million people, which is currently valued at US\$ 354 billion (FAO 2007) and is increasing. In this context, conservation of forest resources and their associated role in alleviating poverty have received renewed attention in recent years (Rao et al. 2004).

Bangladesh is a land-hungry deltaic country in South Asia with an area of $147,570 \mathrm{~km}^{2}$ and is one of the most densely populated countries in the world with a density of 979 people per $\mathrm{km}^{2}$ (BBS 2008). This huge population is putting an enormous pressure on the limited natural resources resulting in the depletion of forest and forest resources at an alarming pace, which has compelled the government to declare logging bans (the first of such bans was imposed on the central Sal forests in the early 1970s and more recently on the Hill Forests in the late 1990s) in different forest areas of the country (GoB 1994). This moratorium has created opportunities for the non-timber forest products (NTFPs) sector to grow and provide an alternative means of livelihood for the rural poor of Bangladesh who are very reliant on forest products.
Among the major NTFPs, medicinal plants (MPs) are the most important in terms of cultivation and policy decisions. MPs are important globally in terms of healthcare as well as a source of money for the people dependent on local forests. There is a rich history and tradition of primary healthcare in local communities based on their knowledge of medicinal plants (Caniago and Siebert 1998). According to FAO (2007), an estimated 121,505 $\mathrm{t}$ of MPs and aromatic products are produced globally out of which 90,181 $\mathrm{t}$ is from Asia and according to Subrat (2002) this figure is increasing by 15 to $20 \%$ annually. Among the 422,000 species of plants in the world $12.5 \%$ are reported to have a medicinal value (Rao et al. 2004). Despite the escalation in the production of synthetic drugs over the last couple of decades, MPs still play a vital role in the life and living of rural and forest dependent communities in many parts of the world, particularly in developing countries (WHO 1990; Badola and Aitken 2003; Rao et al. 2004).

Commercial cultivation of MPs is gaining momentum in Bangladesh due to the potential market for these plants both at home and abroad. Considering the market potential and the shortfall from natural sources it is argued that commercial cultivation could provide a good alternative and enduring livelihood for local communities as well as protecting the natural resource base of MPs. However, there is very limited information on MPs, especially their socio-economic attributes, policy imperatives and research issues in the context of Bangladesh (Khan and Rashid 2006). 
Farmers' hopes and aspirations are often ignored in formulating plans and programs and hence the issues of livelihood remain unexplored (Brown 2003). There has been a very limited effort to explore the reality and issues related to the cultivation of MPs and its management in the field. Most of the research and studies remain undocumented and disorganized with little attempt to synthesize the key findings of these studies (Khan and Rashid 2006). There are very few studies on the socio-economic status, market potential and policy attributes of MPs (Shahidullah and Haque 2010). The policies on sustainable utilization of medicinal plants are also not well defined and in some cases non-existent. Considering the potential of learning from the experiences of other countries and regions, sustainable management of MPs requires urgent support and attention.

Collective cooperation in the governance of natural resource management (NRM) is receiving increasing attention worldwide. Collaborative management of protected forests is a good example of this paradigm shift in resource governance (Mukul et al. 2012; Rashid et al. 2013). The present study was conducted to determine the various dimensions of the cultivation of MPs by farmers. Planting to management, conservation to marketing, farmers cooperatives to microcredit support, land use systems etc. are the salient objectives of this study.

This study aims to determine the current status and management of the MP sector in Bangladesh with a view to suggesting a better way of sustainably cultivating MPs. More specifically, it attempts to determine the field level practices and challenges in terms of overall management of the production of MPs, which will ensure a successful future for this promising sector.

\section{Materials and Methods}

This study mainly focused on practices at field level and challenges faced by farmers in terms of cultivation, management and related issues of research and policy based on a questionnaire and review of secondary information.

\section{Study Site}

This study addressed specific target groups i.e. farmers, traders and traditional healers. The views of respondents to a questionnaire and field visits to farmers to determine their experiences of cultivating MPs and related activities were collected. This was done in a northern district of Bangladesh, named Natore, which is important in terms of the cultivation of MPs (Fig. 1). Laxmipur Kholabaria Union ${ }^{1}$ of Natore district ${ }^{2}$ is the village that

1 The lowest administrative unit of local government in rural areas of Bangladesh.

2 Local administrative units under the supervision of the division. There are 64 districts in Bangladesh. Each district has several sub-districts called Thana.

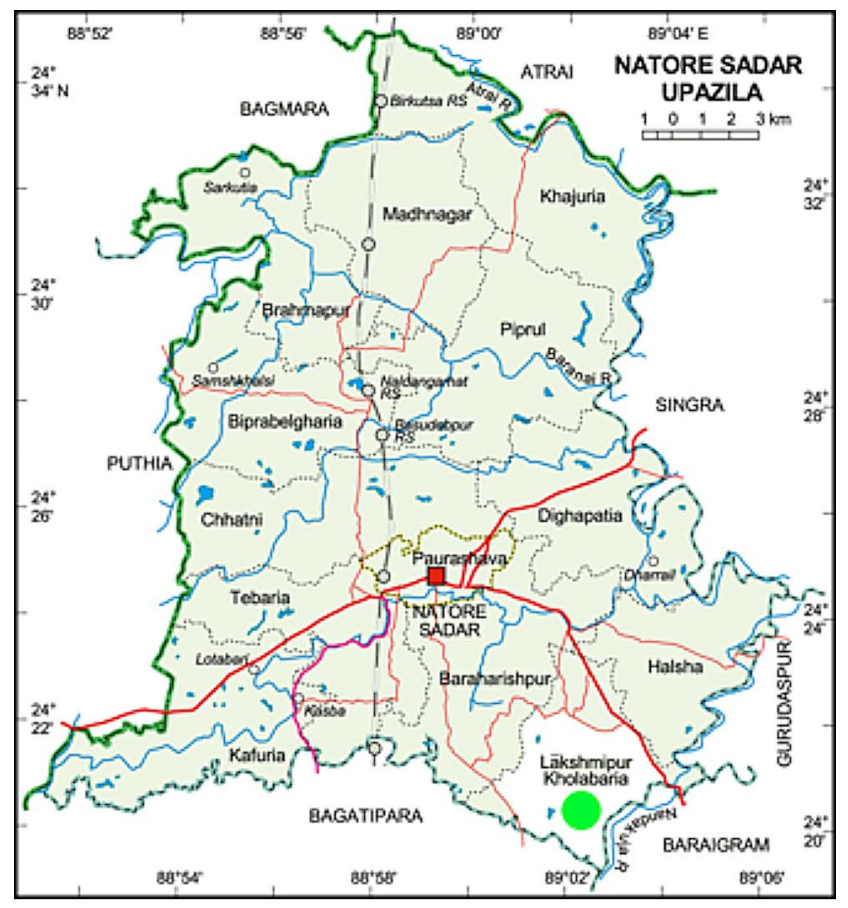

Fig. 1 Map showing the location of the study site (Laxmipur Kholabaria Union of Natore Sadar Thana).

pioneered the commercial cultivation of MPs along with traditional agricultural practices, especially the growing of Aloe vera L. This study was conducted between August and December 2008. Natore consists mostly of an alluvial plain crisscrossed by rivers and with many water-bodies under the jurisdiction of Rajshahi division.

During the survey, a semi-structured (open-ended) questionnaire was used to collect information (Flick 2006). Apart from the questionnaire, focused group discussions (FGDs) were arranged with farmers, Bepari ${ }^{3}$, Kabiraj ${ }^{4}$ and other stakeholders.

\section{Sample Size and Sampling}

The present study was conducted in an area of a northern district of Bangladesh. The detailed methodology is described herewith:

Twenty eight farmers were interviewed, which represents $25 \%$ of those in the study area. The sample population was selected after a daylong meeting with about 50 villagers representing different professions and interest groups (farmers, local traders, kabiraj, teachers and local government officials). Twenty farmers were selected during the meeting because they cultivated MPs and the remaining eight were selected in the field while surveying the initially selected 20 farmers. The farms selected were grouped into one of four categories, namely marginal, poor, medium and large farmers. The classification of farms was done based on land ownership (marginal farms consisted of less than 0.13 ha, poor farmers 0.13

3 Person who buys medicinal plants and/or plant parts from the small farmers or collectors and sells them on to the wholesalers or industrial processing units.

4 Traditional healer or practitioner within the Ayurvedic system. 
to 0.65 ha, medium farmers between 0.65 and 1.3 ha and large farmers more than 1.3 ha farmland). Among the respondents nine of the farms were in each of the marginal and small farm categories and five each in the medium and large farmer categories. Among the respondents 24 were male and four female. The female respondents farmed marginal or small farms.

The female farmers were reluctant to be interviewed in the field, so these interviews took place in their respective households. The interview time varied depending on the context of the interview, whether in the field or in a homestead. In general the field interviews took longer since the farmers and the research team was simultaneously engaged in discussing and recording. The average time spent on each survey was 2.45 hours.

Apart from the questionnaire, dual moderator FGDs were organized (Marshall and Rossman 1999). Two FGDs were arranged at the Natore study site (farmers, Beparis and Kabirajs were included). The first FGD included six local traders (Beparis), who provided information on the markets and marketing channels for MPs and their products produced in the study area while the second FGD included five Kabiraj who provided information on their profession and related issues. The outcomes of the FGDs were summarized using inductive coding (Frankfort-Nachmias and Nachmias 1996; Flick 2006), which grouped the outcomes based on similarity or dissimilarity of the opinions and priorities of the respondents.

\section{Data Analysis}

The survey produced mostly qualitative data and therefore, the analysis was based on descriptive statistics. The information collected by interviewing farmers and the questionnaire were grouped and posted into excel data sheet to be analyzed using a statistical package used in social science studies (SPSS Version 15.0). Data obtained from respondents were further analyzed using inductive coding (Frankfort-Nachmias and Nachmias 1996; Flick 2006). The information obtained from the questionnaire was compiled and coded with numbers ranging mostly from 1-4 or more where applicable. In case of "yes" or "no" answers a 1 and 0 code was used throughout this study. This inductive coding enabled us to obtain additional information on the issues addressed. The most frequently mentioned responses included the coding to analyze the data to conclude. Descriptive statistics were also used to summarize and illustrate the objectives of this study.

\section{Results}

The commercial cultivation of MPs started in the early 1990s in the Natore district and is now spreading to other parts of Bangladesh. In the study area several different species are cultivated and among them A. vera, Bombax ceiba L., Asparagus racemosus L., Withania somnifera
Dunal., Ipomoea digitata L. and Scoparia dulcis L. are the most important. Land with sandy loam soil, good drainage and exposed to direct sunlight is the most suitable for cultivation of these species.

The cultivators of MPs are mostly traditional farmers who grew agricultural crops, e.g. rice, wheat, and sugarcane before cultivating MPs. The cultivation of MPs is often a labour-intensive and involves the whole family working as labourers in addition to hired labour when needed. Women mostly do the weeding and harvesting although socioculturally women do not usually do this kind of work in the study area.

\section{Management of Medicinal Plants - Related Issues Cultivation of medicinal plants as a profession}

In the study area, farmers have cultivated MPs for periods varying from 2 to 20 years. For the majority of the farmers cultivating MPs it was not their primary concern and only $29 \%$ cultivated only MPs. Most of the marginal farmers cultivate mainly only MPs. Of the nine marginal farmers included in this survey, for six of them it was their chief means of livelihood.

The income from cultivation and related activities associated with MPs was significantly correlated with the size of farmers' households $(0.531, \mathrm{p}<0.01)$ and the amount of land they owned $(0.443, \mathrm{p}<0.05)$. The yearly income from the cultivation of MPs ranged from 457 to 4810 US\$ (1 US\$=76.5 Taka in July, 2013).

\section{Medicinal plants commonly cultivated in the study area}

The Natore area is famous for its cultivation of $A$. vera and many people refer to Natore as the Aloe village, although more and more species are being cultivated in this area. The commonest commercially cultivated MPs based on land coverage are A. vera (38\%), B. ceiba (27\%), A. racemosus (16\%) and others including $W$. somnifera, Adhatoda vasica Nees., Ocimum sanctum L., I. digitata and Abroma augusta L. make up 19\%. Detailed lists of the commonly cultivated MPs are presented in Appendix -I.

\section{Sources of the Material Planted}

Farmers normally plant seedlings of $A$. vera, while B. ceiba and A. racemosus are raised from seed. A large percentage of the farmers (46\%) depend on other farmers and markets for seed and seedlings, with the majority depending on local farmers.

\section{Disease Management}

The MPs in the study area suffer from diseases but so far there have been no serious outbreaks. During the survey, farmers mentioned three specific problems, root rot in A. vera and W. somnifera, leaf spot in A. vera and scale insects on $A$. vasica.

\section{Factors affecting cultivation}

The farmers cultivate MPs commercially as they give a quick economic return. Of the 28 farmers 17 mentioned 


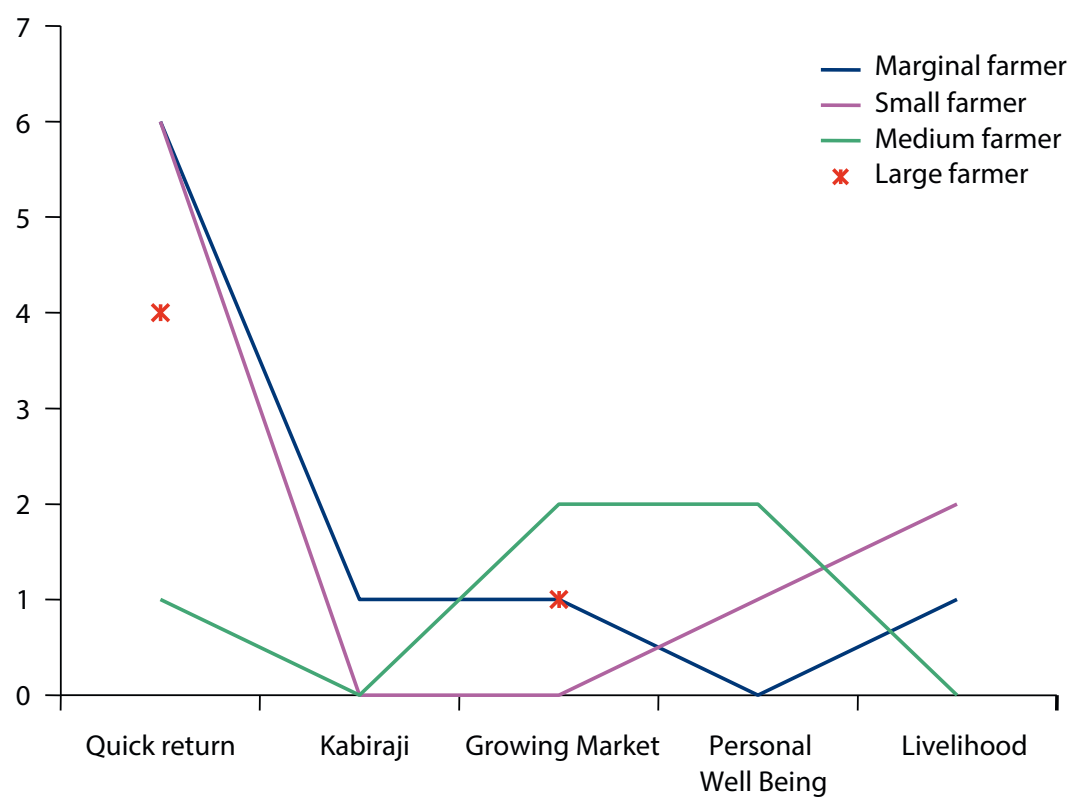

Fig. 2 Factors motivating farmers to cultivate medicinal plants.

"quick returns" as their main reason for cultivating these plants followed by "market potential" (four farmers). The remaining two did so because of positive experience of "neighbours" and their role as "traditional medicines". Detailed views of farmers grouped based on the size of their farms are presented in Fig. 2.

\section{Farming of Medicinal Plants as a Means of Earning a Livelihood}

This study revealed that $71.5 \%$ of the farmers viewed MPs as a viable way of earning a livelihood provided a pro-farmer forest policy is practiced and $28.5 \%$ agreed it was currently a potential source of a livelihood. However, despite the differences in opinion, it is apparent from the field visits that the socio-economic status of the farmers growing MPs has improved significantly.

\section{Use and fragmentation of the land}

The use of the land in the study area is similar to that in other parts of Bangladesh. Farmers utilize their land for agricultural practices such as paddy cultivation, winter vegetables and horticultural crops. In addition, farmers use suitable land for the cultivation of MPs, especially A. vera, B. ceiba and A. racemosus. For the farmers

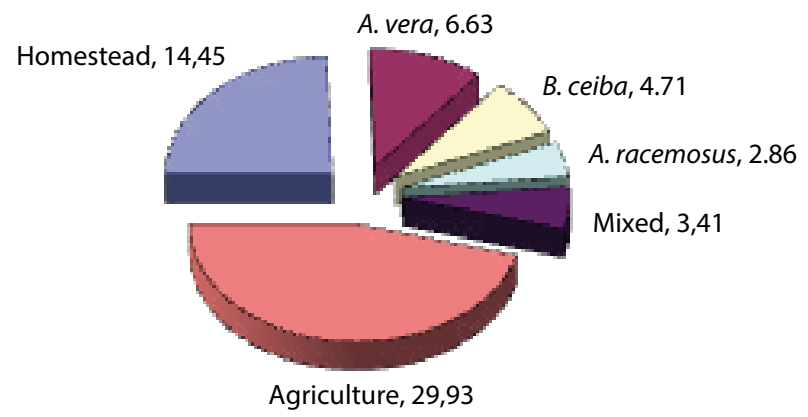

Fig. 3 Pie chart showing the land use type (in\%) in the study area. interviewed most of their land was used for traditional agriculture (26.9\%) followed by land for the homestead (14.5\%). The percentage of land use for cultivating different medicinal plants is shown in Fig. 3.

\section{Criteria for Leasing Land}

More and more farmers are becoming interested in growing MPs on land they own, but the availability of suitable land is very limited and thus the leasing of land is becoming increasingly popular. There are two ways in which it is possible to lease land in the study area. The first is based on a cash payment to the landowner (usually US\$ 2,417 for one ha of land). By doing this the leaseholder can enjoy the land until the landowner is able to pay back the money to the leaseholder. The minimum period is one year or one growing season. The leaseholder only needs to pay the annual land tax, which is approximately US\$ 21 per year. A legal agreement is signed on a judicial stamp to validate the leasing agreement. The other type is an annual lease based on mutual trust, whereby the leaseholder has to pay US $\$ 218$ per ha annually to the landowner and consequently can continue to use the land until the owner gives notice well ahead of the next growing season.

\section{Division of Land Ownership}

Land fragmentation due to the acute shortage of land is a growing concern in Bangladesh. Each farm is divided among the siblings at their maturity. Therefore, in the study area the availability of suitable land for cultivating MPs is being reduced day by day in terms of per capita ratio. Such fragmentation farms limit the sustainable growth in the cultivation of MPs in the study area. Twenty of the farmers fully realized the challenges that will have to be faced in a near future, and four stressed that they were already victims of land fragmentation as they 


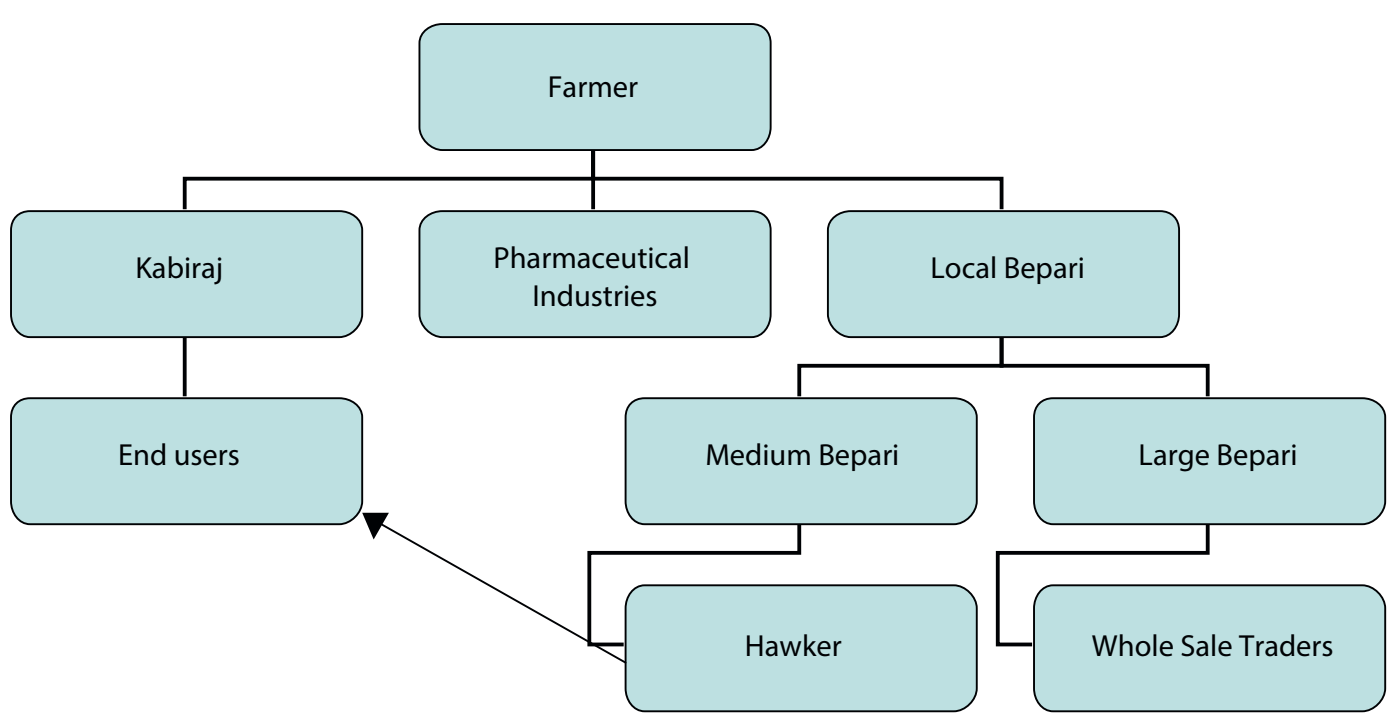

Fig. 4 Flow chart showing medicinal plants marketing system in the study area.

inherited little land from their parents. The remaining four farmers viewed it as a manageable problem as they have large farms.

\section{Market and system of marketing}

In terms of the potential for marketing MPs it was thought to be either potentially "good", "very good" or "promising". Thirty-six per cent indicated it was potentially "very good", $35 \%$ good and $29 \%$ promising with potential for further growth.

Whole medicinal plants and products (root powder, bark powder etc.) are mainly marketed either via local Bepari or by direct sale. About $59 \%$ of the farmers use both methods, $26 \%$ depend exclusively on local Bepari and $15 \%$ sell their products directly to purchasers. In the case of $A$. vera it is usually fresh leaves that are marketed whereas in the case of other species both fresh and dried products are available for sale. Regarding the potential for further processing of plants and plant products, all farmers were keen that the necessary technology, finance, infrastructure and marketing be provided. Since 59\% of the farmers depend on Bepari for selling their products their role is crucial.

The market value of MPs and their products varies significantly depending on the availability and demand. The principal product, leaves of $A$. vera, are produced in response to demand and then sold by the local Bepari. The income from the cultivation of MPs and related activities is twice that from traditional farming i.e. rice cultivation. While discussing the marketing of MPs in the study area in general, the view of the Bepari was that it was disorganized and mainly controlled by city wholesalers (Fig. 4). In discussions the existing marketing system the farmers mentioned the following shortcomings:

- absence of governmental supervision resulting in the poor cultivation and management of MPs, which influenced the price;
- absence of an effective farmers' cooperative for protecting the rights of the farmers;

- poor networking between farmers and potential buyers due to fragile value chain;

- absence of infrastructure and storage facilities for keeping excess produce.

During the FGDs the Beparis suggested the following measures for improving the existing methods of marketing:

- bring primary and secondary methods of processing to the farmers;

- provide buildings for farmers for the primary processing of MPs;

- get government and other organizations to provide credit and infrastructural support for farmers and traders;

- formulate a policy and action plan for the NTFP sector;

- introduce potential buyers to the farmers and producers, i.e. big wholesalers and pharmaceutical companies.

\section{Farmers' cooperative}

A farmers' cooperative named the Kholabaria Herbal Medicine Village Organization was established in 2004. This cooperative has 170 members including farmers, local traders, small vendors and Kabiraj. Of the farmers in this study 23 are members of the cooperative and five are not. The members pay a monthly fee of TK $10^{5}$ and meet once a month. The idea behind establishing the cooperative is to protect farmer's rights and interests. 54\% of the farmers were satisfied with the performance of the cooperative. However, 32\% expressed concerns about

5 Local currency of Bangladesh. One taka is equivalent to 76.5 US\$ (as of July, 2013). 
conflicts of interest and abuse of power by the representatives and 14\% believe that the current representatives are inefficient and to some extent biased in protecting their rights and meeting their demands. They mentioned the poor institutional capacity of the cooperative, which results in poor prices for their produce and provides scope for exploitation by middlemen.

\section{Micro-credit support}

Mixed opinions were expressed concerning the level of micro-credit support for the cultivation of MPs. Marginal and small farmers demanded credit support since they often lack capital for buying seedlings, fertilizer etc, while the medium and large farmers were concerned about the restraining effect of the high interest rate levied on micro credit.

\section{Institutional Attributes of the Cultivation of MPs and Related Activities}

Cultivation of medicinal plants as a means of a livelihood is a fairly new concept in Bangladesh even though it started informally a decade ago. Commercial projects still in an initial stage of development demand thoughtful and constant monitoring and support from government. However, the interviews revealed that government intervention is lacking in the study area. Regarding NGO support, the farmers indicate it is inadequate. Only one local organization, LUSTER, worked with the farmers cultivating MPs assisted by the Swiss Development Cooperation and International Finance Corporation.

\section{Discussion}

The present study focused on selected problems experienced in the field in cultivating and marketing MPs in the study area. Due to a logging ban (imposed in late 1990s) in the natural forests of Bangladesh, the pressure is now on NTFP to provide a livelihood for the poor villagers. An alternative livelihood, the commercial cultivation of important MPs would not only provide such a livelihood but also contribute to species conservation.

\section{Sustainable Livelihood and Conservation}

Cultivation of medicinal plants and its management demand adequate attention from the key stakeholders including farmers, researchers, policy planners and entrepreneurs if the desired goal of sustainability is to be achieved. It is possible to improve the livelihood of rural marginal farmers by creating an environment that is supportive of the commercial cultivation of MPs. This study has revealed the potential of MPs as a means of improving the livelihoods of farmers in the study area. Seventeen farmers that changed from traditional agriculture to cultivating MPs increased their incomes. Today many marginal and poor farmers are entirely dependent on income from cultivating MPs, which traditional agriculture failed to provide. Five farmers (marginal and poor) even leased land in order to increase their output of MPs and income. This could be the basis for formulating a project for increasing the incomes of poor and marginal farmers.

Since $A$. vera is extensively cultivated in the study area there are reports of diseased plants, which if not treated in time may affect the quality and economic value of the harvest. There is a need for research and intervention policies. Commercial cultivation of MPs of only a few species in the Laxmipur Kholabaria Union may affect the sustainability of this practice and indicates the need to diversify. However, we found that marginal and small farmers are quite aware of this problem. In order to combat infection with diseases they are practicing mixed cropping, e.g. by planting $B$. ceiba along with banana, mango and guava, and $W$. somnifera with winter crops.

\section{Market and Marketing}

In general, the market for MPs in Bangladesh is disorganized and heavily influenced by middlemen. However, the market potential varies based on the demand and characteristics of the market as noted by Arnold and Pérez (1998). The farmers in the study area marketed their products mainly either by selling them themselves or by getting the local Bepari to sell the produce for them. A majority of the farmers mentioned the influence of intermediaries and the absence of any state interventions as drawbacks in the marketing system. Due to influence of local traders and wholesalers the farmers were often compelled to sign irrational agreements that forced them to sell their products at a fixed price irrespective of market demand or changes in price. As a result during times of high prices and demand, farmers lost their share of the profit. On the other hand, local Beparis mentioned the manipulative role of city wholesalers as one of the challenges of marketing. The situation is further exacerbated by conventional and often inefficient cultivation, management and processing of MPs along with poor networking with potential buyers.

The development of a credible marketing system is often hampered by poor communications and absence of relevant infrastructure (notably lack of storage facilities) and lack of low interest and easy accessible credit for farmers. In order to ensure growth and sustainability of the MP sector, a credible system of marketing is a prerequisite, a view also shared by Khan and Rashid 2006.

The increase in value obtained by processing raw material has to be balanced against the cost in time required. This can be done by using biotechnology to produce uniform high quality planting materials and adding value by semi-processing raw material using modern drying, grading and storage techniques as mentioned by Calixto (2000). 


\section{Training and Capacity Building}

The farmers in the study area urged that they be shown how to improve their skills in cultivating and primary processing of MPs so that they can more effectively compete in the market place. Absence of institutional support is another factor limiting farmers from exploiting different markets and contacting corporate buyers like pharmaceutical industries. Large pharmaceutical companies are interested in bulk procuring of MPs of high quality. To improve their skills in cultivation, management and primary processing they need to be appropriately trained.

Support at both farm and institutional levels in the commercial development of nurseries and plantations for the ecologically viable production and primary processing of medicinal plants are needed. The farmers and Kabiraj are becoming increasingly concerned about the poor quality of the planting material. Research institutions like Bangladesh Forest Research Institute (BFRI) and Bangladesh Forest Department (BFD) need to ensure the high quality of the material planted by farmers otherwise the desired growth of the MP sector will continue to be threatened and confined only to local communities. In this regard local organizations with substantial support from institutions can play a significant role in the technical and commercial training of the growers.

\section{Infrastructural Constraints}

The farmers in the study area need facilities for storing and preserving their excess products, especially the leaves of $A$. vera during the rainy season when monsoon rain damages the leaves and during the winter when the demand drops considerably and greatly affects the price. Provision of a regional storage facility would help farmers to preserve their produce until it can be sold at a better price. A significant number of farmers have expressed an interest in switching to cultivating MPs because of its socio-economic and conservation benefits. This should be recognized and given adequate support.

\section{Credit and Cooperation}

Micro financing at affordable interest rates would help the farmers fund the cost of cultivation. However, there are mixed views on the micro credit support available in the study area. The government could play a decisive role in arranging for farmers the easy access to credit at low rates of interest. A strictly monitored pro-farmer policy would be important in this regard.

\section{Cultivation and Management Issues}

Although the commercial cultivation of MPs is increasing there is growing concern about the quality of the products required to be competitive in local and global markets. Diseases and pests are important in determining the quality of farmers' produce. The farmers report an increase in the incidence of several diseases, like root rot, leaf spots and scale insects, affecting the quality and price of their products. While discussing this issue with the leading pharmaceutical companies, they also raised concern regarding the quality in terms of purity of the raw materials, which force them to look for regional markets to procure material of high quality.

Availability of plant material of high quality is crucial and needs to be addressed. This study revealed that $46 \%$ of the farmers depend both on other farmers and markets for procuring plant material for cultivation, while the majorities mainly depend on neighboring farmers. Since farmers are not sure about the quality of the procured seed and seedlings this increases the possibility of disease or pests destroying their crops. Bangladesh Forest Department in collaboration with research institutes should take the lead in ensuring the quality of the plant material cultivated. Grass root organizations can be used to disseminate the technology at the farmer level. Ensuring a regular supply of high quality material for planting at affordable price would probably increase both the quality and yield. Considering that the availability of resources for farmers is limited a similar approach to that used in Taungya ${ }^{6}$, in which MPs are cultivated in the forest, could be adopted.

\section{Conclusion}

This study revealed that one key challenge in managing the production of MPs is to integrate the needs of farmers with available knowledge and technological support. Currently there is a great need to integrate economic and ecological requirements. Furthermore, since natural forests are fast disappearing there is an urgent need to protect the remaining forests. In doing this it is important to take into consideration the livelihood of farmers and interests of other stakeholders in developing coordinated management plans.

Community organizations should play a major role in formulating policies; since they often are the only ones in direct contact with the farmers and aware of the realities at field level. However, in Bangladesh and other parts of south Asia they have only had a marginal role (Gopalakrishnan et al. 2005). In some cases the process of formulating a policy is more likely to protect the interests of the local political elite rather than the needs of farmers (see for example, Bhattacharya and Hayat 2004; Kala et al. 2006). However, there have been some successes in protected area governance in Bangladesh achieved by collaborative management.

Our field study revealed that all the important stakeholders, including farmers, traditional healers, researchers and community organizations, thought that in order to realize the full potential of this sector, especially in terms of sustaining community livelihood and conserva-

6 Taungya derived from the Burmese term taung, which means hill and $y a$, which means cultivation. It is the form of hill cultivation widely practiced by farmers of the swidden tribe in the Chittagong Hills. 
tion of biodiversity, it was very important to create local institutions to train and represent the farmers. Development of a local institution, which represents and headed by farmers', is important in this regard. Detailed guidelines for harvesting, storage, drying, grading and primary processing are necessary for adding value to their products. Furthermore improving value by economic coordination is also deemed necessary as is mentioned in other studies (i.e. Shahidullah and Haque 2010). Partnerships between various stakeholders, mainly farmers, community organizations, industries and research and development institutions, are seen as the way to achieve this (Shinwari and Khan 2000; APFD 2002). Based on our experiences in the field and on feedback and the opinions of associated stakeholders we reached the following conclusions about the economical, ecological and institutional aspects of the sustainable production of medicinal plants:

1. Cultivation of medicinal plants in homesteads and agricultural fields can support the livelihood of the farmers of Natore.

2. Diseases need to be carefully managed aided by the research on these diseases carried out by research institutions. Adoption of mixed cropping might significantly reduce the incidence of disease and optimize the utilization of the land, which in this area is a scarce resource.

3. Transport, storage and other infrastructures need to be developed in order to sustain the value of this sector.

4. Micro-credit support for marginal farmers and small traders needs to be provided by a network of NGOs, large pharmaceutical companies and other major stakeholders.

5. It is also necessary to create a reliable database of the status, habitat requirements, extent of exploitation and the market for different species of plants with the help of local user groups and collaboration of researcher, policymakers, NGOs and pharmaceutical industries.

6. Strengthen the ex-situ and in-situ efforts to develop a sustainable supply of high quality plants for traditional healers and cultivators.

7. Institutionalize the farmers' cooperatives and arranging capacity building of all stakeholders engaged in cultivation, management, value adding and marketing aspect through devising supportive policy.

8. More research is needed, especially on the socio-economic aspects and the role of the cultivation of MPs in the local economy and conservation of biodiversity.

\section{Acknowledgements}

This paper is based on the outcome of the theses submitted for Master Degrees in Environmental Science, Swedish University of Agricultural Sciences, Uppsala,
Sweden. The field work was funded by the SIDA. However the views presented in this article are the sole responsibility of the authors.

\section{REFERENCES}

APFD (2002) Sustainable harvesting, conservation, cultivation and marketing linkages for medicinal plants of Andrha Pradesh Community Forest Management Project. Foundation for Revitalization of Local Traditions.

Arnold JEM, Pérez MR (1998) The role of non-timber forest products in conservation and development. In: Wollenberg E, Ingles A (eds) Income from the forest - Methods for the development and conservation of forest products for local communities. CIFOR, Indonesia.

Badola HK, Aitken S (2003) The Himalayas of India: A treasury of medicinal plants under seize. Biodiversity 4: 3-13.

BBS (2008) Statistical yearbook of Bangladesh' Ministry of Planning, Government of the People's Republic of Bangladesh, Agargaon, Dhaka.

Bhattacharya P, Hayat SF (2004) Sustainable NTFP management for rural development: A case from Madhya Pradesh, India. Int Forest Rev 6: 161-168.

Brown K (2003) Three challenges for a real people-centred conservation. Global Ecol Biogeogr 12: 89-92.

Calixto JB (2000) Efficacy, safety, quality control, marketing and regulatory guidelines for herbal medicines (Phytotherapeutic agents). Braz J Med Biol Res 33: 179-189.

Caniago I, Siebert SF (1998) Medicinal plant ecology, knowledge and conservation in Kalimantan, Indonesia. Econ Bot 52: 229-250.

FAO (2007) State of the world's forest Food and Agriculture Organization of the United Nation.

Flick U (2006) An introduction to qualitative research. Sage Publications. 3rd edn.

Frankfort-Nachmias C, Nachmias D (1996) Research methods in the social sciences. Arnold publication, London.

Gopalakrishnan C, Wickramasinghe WAR, Gunatilake HM, Illukpitiya P (2005) Estimating the demand for the non-timber forest products among rural communities: a case study from the Sinharaja Rain Forest region Sri Lanka. Agroforest Syst 65: $13-22$.

Iftekhar MS (2006) Forestry in Bangladesh: An overview. J Forest 104: 148-153.

Kala CP, Dhyani PP, Sajwan BS (2006) Developing the medicinal plants sector in northern India: challenges and opportunities. J Ethnobiol Ethnomed 2: 32.

Khan NA, Rashid AZMM (2006) A study on the indigenous medicinal plants and healing practices in the Chittagong Hill Tracts (Bangladesh). Afr J Tradit Complem 3: 37-47.

Marshall C, Rossman GB (1999) Designing qualitative research. Sage Publication, UK.

Mukul SA, Rashid AZMM, Quazi SA, Uddin MB, Fox J (2012) Local People's Responses to Co-management Regime in the Protected Areas: A Case Study from Satchari National Park, Bangladesh. Forests, Trees and Livelihoods 21: 16-29.

Rashid AZMM, Craig D, Mukul SA, Khan NA (2013) A Journey Towards Shared Governance: Status and Prospects for Collaborative Management in the Protected Areas of Bangladesh. J Forest Res 24: 599-605.

Rao MR, Palada MC, Becker BN (2004) Medicinal and aromatic plants in agroforestry systems. Agroforest Syst 61-62: 107-122. 
Shahidullah AKM, Haque CE (2010) Linking medicinal plant production with livelihood enhancement in Bangladesh: Implications of a vertically integrated value chain. J Transdiscipl Environ Stud 9: 1-18.

Shinwari MI, Khan MA (2000) Folk use of medicinal herbs of Margala Hills National Park, Islamabad. J Ethnopharmacol 69: 45-56.

Subrat N (2002) Ayurbedic and herbal products industry: an overview. Paper presented in a workshop on wise practice and ex- perimental learning in the conservation and management of Himalayan medicinal plants, Kathmandu, Nepal, 15-20 December 2002.

WHO (1990) A manual for health workers in South-East Asia SEARO regional health paper No. 19. World Health Organization.

World Bank (2002) A revised forest strategy for the World Bank Group. World Bank, Washington DC.

Appendix 1 List of commonly cultivated and available MPs in the Natore study area

\begin{tabular}{|c|c|c|}
\hline Local Name & Scientific Name & Family \\
\hline Ulatkambal & Abroma augusta $\mathrm{L}$. & Sterculiaceae \\
\hline Apang & Achyranthes aspera $\mathrm{L}$. & Amaranthaceae \\
\hline Grhitokumari & Aloe vera $\mathrm{L}$. & Liliaceae \\
\hline Kalomegh & Andrographis paniculata Nees. & Acanthaceae \\
\hline Ishwarmul & Aristolochia indica L. & Aristolochiacaeae \\
\hline Shotomuli & Asparagus racemosus L. & Liliaceae \\
\hline Shimul & Bombax ceiba L. & Bombacaceae \\
\hline Hastipolash & Butea superba Roxb. & Papillinaceae \\
\hline Dadmardan & Cassia alata L. & Fabaceae \\
\hline Talmul & Curculigo orchioides Gaertn. & Amaryllidaceae \\
\hline Anantamul & Hemidesmus indicus R. Br. & Asclepiadaceae \\
\hline Bhuikumra & Ipomoea digitata L. & Convolvulaceae \\
\hline Alkusi & Mucuna pruriens (L.) DC. & Fabaceae \\
\hline Ghandabadali & Paederia foetida $\mathrm{L}$. & Rubiaceae \\
\hline Kayamul & Pandanus odoratissimus L. f. & Pandanaceae \\
\hline Peepul & Piper longum L. & Piperaceae \\
\hline Sarpagandha & Rauwolfia serpentina Benth. & Apocynaceae \\
\hline Misridana & Scoparia dulcis L. & Scrophulariacae \\
\hline Arshawgandha & Withania somnifera Dunal. & Solanaceae \\
\hline Nishinda & Vitex negundo L. & Verbenaceae \\
\hline
\end{tabular}

